\title{
$\mathrm{FDM}$ 해석에 의한 구체축열시스템(TABS)의 난방운전시 방열 특성 분석
}

\author{
임 재 한 ${ }^{\dagger}$, 송 진 희, 구 보 경, 송 승 영, 성 윤 복 ${ }^{*}$ \\ 이화여자대학교 건축공학과, ${ }^{*}$ 한국건설교통기술평가원
}

\section{Characteristic of Thermal Output of Thermally Activated Building System During the Heating Operation According to FDM Analysis}

\author{
Jae-Han Lim $^{\dagger}$, Jin-Hee Song, Bo-Kyoung Koo, Seung-Yeong Song, Yoon-Bok Senog* \\ Department of Architectural Engineering, Ewha Womans University, Seoul 120-750, Korea \\ "Korea Institute of Construction and Transportation Technology Evaluation and Planning, Kyeonggi-Do \\ 431-060, Korea
}

(Received December 5, 2011; revision received December 20, 2011)

\begin{abstract}
This study is focused on the evaluation of thermal output of TABS (Thermally Activated Building System). The aim of this study is to evaluate TABS in terms of the temperature difference between heating medium supply temperature $\left(T_{s}\right)$ and return temperature $\left(T_{r}\right)$, thermal output and the surface temperature distribution according to the design flow rate and the design flow temperature. Through the transient heat transfer simulation using temperature calculation using Crank-Nicolson FDM using Physibel Voltra 6.0 W, the temperature difference between $T_{s}$ and $T_{r}$, thermal output and the surface temperature distribution of specific TABS was calculated and evaluated. The results show that specific thermal output and temperature difference at $60^{\circ} \mathrm{C}$ of supply water temperature were about $162 \mathrm{~W} / \mathrm{m}^{2}, 13.6^{\circ} \mathrm{C}$ respectively
\end{abstract}

Key words: Thermally activated building System(구체축열시스템), Thermal output(방열량), Finite difference method(유한차분법), Supply water temperature(공급온수온도)

\section{1. 서 론}

\section{1 연구의 배경}

일반적으로 복사냉난방시스템은 패널이나 바닥 에 열전도율이 양호한 배관이나 방열판 등을 이용 해 냉난방하는 방식을 말한다. 복사냉난방시스템은 천장패널이나 모세관 튜브, 콘크리트 구조체 등을 활용하여 냉난방부하 중 현열부하를 제거하는 것으

† Corresponding author

Tel.: +82-2-3277-6874; fax: +82-2-3277-2396

E-mail address: limit0@ewha.ac.kr
로서, 지금까지 국내에서는 기존난방에 활용되어온 온돌구조체를 냉방에 활용하기 위한 연구가 진행되 었다. 이와 마찬가지로 콘크리트 구조체를 이용하 는 구체축열시스템은 배관을 콘크리트 내에 매설하 여 건물 구조체를 축열(냉)함으로써 부하를 제거하 거나 시간차에 의해 피크부하를 줄일 수 있는 시스 템이다. 국내에서는 적용된 사례가 많지 않지만, 최 근 유럽을 중심으로 저에너지 친환경 건축물 프로 젝트에 에너지 절약기술로서 대형건물이나 공항, 컨벤션센터 등의 건물에 널리 사용되고 있다.

TABS(Thermally Activated Building System) 또는 $\mathrm{CCA}$ (Concrete Core Activation) 시스템으로 
알려진 구체축열시스템은 복사(radiation)에 의해 건물을 냉난방하는 공조시스템이다. 일반적으로 저 위의 열원, 즉 신재생에너지나 미활용온도차에너지 와 같은 저온 난방 열원과 고온 냉방 열원을 적용 할 수 있으며, 별도의 축열체를 두지 않고 건물 구 조체를 축열체로 사용한다는 점에서 일반적인 빙축 열시스템이나 수축열시스템과는 구분된다. 최근 국 내에서도 $\mathrm{E}$ 대학 건물에서 콘크리트 슬래브 내에 배 관을 매설하여 지열시스템과 연계한 구체축열시스 템이 적용되었으며, 국내 설계 프로젝트에서도 점 차 보급이 시도되고 있는 추세이지만 실제 적용 사 례는 아직까지 활발하지 않은 실정이다. 이는 구체 축열시스템을 건물에 적용하기 위한 기본적인 설계 자료가 체계적으로 제공되지 못하고 있으며, 실제 운전에서 콘크리트 열용량에 따른 시간지연 및 방 열 특성에 대한 기초자료가 부족하기 때문이다. 그 러므로 본 연구에서는 기존 국내 $\mathrm{E}$ 대학 건물에 적 용된 구체축열시스템을 대상으로 동적 전열해석을 통해 난방시 운전조건 및 구조체의 축열량에 따른 방열량 특성을 분석하여 운영 및 제어의 기초 자료 로 활용하고자 하였다.

본 연구에서는 구체축열시스템의 방열 특성을 평 가하기 위해 유한차분법에 의한 동적 전열해석 프 로그램을 활용하여 기존 사례 건물의 구체축열시스 템을 대상으로 운전조건에 따라 방열량을 산출하여 제어 및 운영의 기초자료를 제시하였다.

\section{2. 구체축열시스템의 방열성능 평가 시뮬레이션}

본 연구에서는 3 차원 비정상상태 시뮬레이션을 통해 구체축열시스템 난방 시의 온수 공급온도 및 설계유량의 변화에 따른 방열량과 배관의 환수온도 강하량, 방열면의 표면온도 분포특성을 평가하는 것으로 하였다. 3 차원 비정상상태 전열해석 도구로 써 Physibel Voltra 6.0 W 프로그램을 이용하였다. Physibel Voltra 6.0 W 프로그램은 3차원 비정상상 태 전열해석 프로그램으로 열평형 방정식을 유한차 분법에 의해 이산화하여 풀어줌으로써 복잡한 건물 부위에서의 정밀 전열해석이 가능한 신뢰도가 높은 프로그램이다.

\section{1 구체축열시스템의 평가모델}

본 연구에서는 국내 $\mathrm{E}$ 대학 건물에 적용되어 있는 구체축열시스템을 대상으로 하며, 평가모델은 지하 2 층 강의실 천장에 적용된 구체축열시스템을 대상 으로 하였다. Fig. 1, Fig. 2와 같이 총 길이 $209 \mathrm{~m}$ 의 배관이 $150 \mathrm{~mm}$ 간격으로 콘크리트 구조체에 매 설되어 있으며, 배관 상부 구조체는 “목재바닥+무 근콘크리트+압출법보온판+콘크리트슬래브”로 구성 되었고, 배관 하부 구조체는 콘크리트 슬라브에 노 출 마감으로 방열면으로서 역할을 하고 있다. 그리 고 구체축열시스템의 상부와 하부 공간은 강의실로

Table 1 Supply water temperatures, Flow rates and the thickness of concrete of test cases

\begin{tabular}{c|c|c|c|c}
\hline Test case & $\begin{array}{c}\text { Supply water } \\
\text { temperature }\left({ }^{\circ} \mathrm{C}\right)\end{array}$ & $\begin{array}{c}\text { Flow rate } \\
(\mathrm{LPM})\end{array}$ & $\begin{array}{c}\text { Thickness of concrete } \\
\text { above the pipe layer(mm) }\end{array}$ & $\begin{array}{c}\text { Thickness of concrete } \\
\text { below the pipe layer(mm) }\end{array}$ \\
\hline T1 & 40 & 3 & 200 & 125 \\
\hline T2 & 50 & 3 & 200 & 125 \\
\hline T3 & 60 & 3 & 200 & 125 \\
\hline T4 & 70 & 3 & 200 & 125 \\
\hline T5 & 80 & 3 & 200 & 125 \\
\hline F1 & 60 & 1 & 200 & 125 \\
\hline F2 & 60 & 2 & 200 & 125 \\
\hline F3 & 60 & 3 & 200 & 125 \\
\hline F4 & 60 & 4 & 200 & 125 \\
\hline F5 & 60 & 5 & 200 & 125 \\
\hline F6 & 60 & 6 & 200 & 125 \\
\hline H1 & 60 & 3 & 200 & 100 \\
\hline H2 & 60 & 3 & 200 & \\
\hline H3 & 60 & 3 & 100 & \\
\hline
\end{tabular}




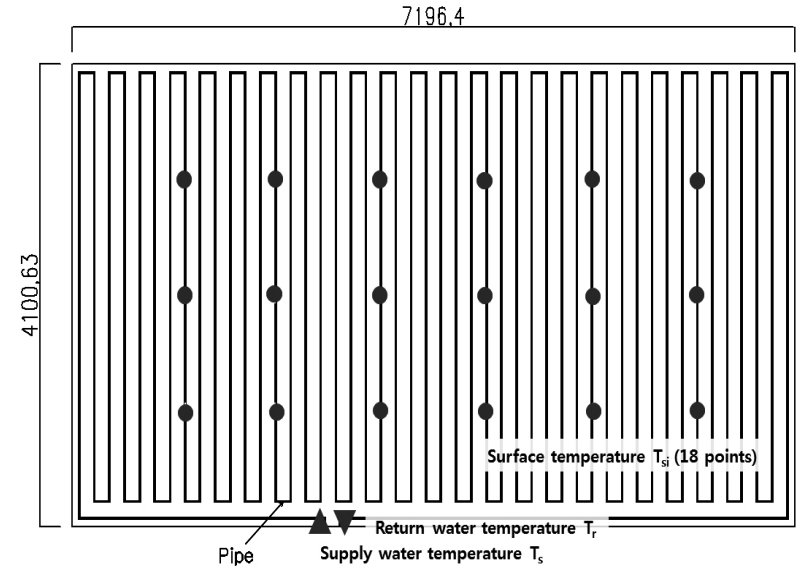

Fig. 1 Pipe layout of TABS in building.

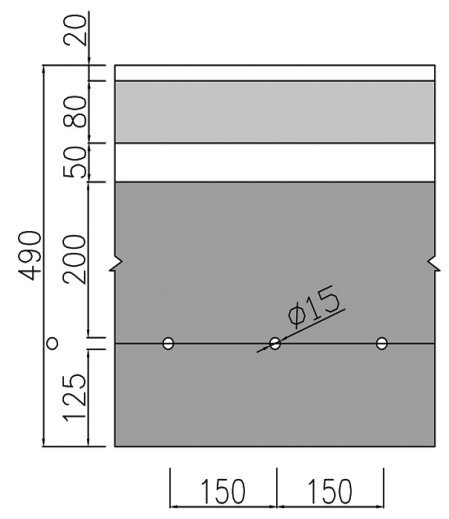

T20 Wooden flooring T80 Plain concrete T50 XPS insulation T200 Concrete Slab CCA Pipe ø15@150 T125 Concrete Slab

Fig. 2 Vertical Section of TABS.

활용되고 있다. 방열특성 분석을 위해 Table 1 과 같 이 온수 공급온도 $60^{\circ} \mathrm{C}$ 기준으로 온수유량 $1,2,3$, $4,5,6 \mathrm{LPM}$ 을 적용한 6 개의 모델과 온수 공급유량 $3 \mathrm{LPM}$ 기준으로 온수 공급온도 $40,50,60,70,8$ $0{ }^{\circ} \mathrm{C}$ 에 대한 5 개 모델을 대상으로 방열량, 환수 온도 강하, 표면온도 특성에 대해 분석하였다. 또한 콘크 리트 구조체의 축열량에 따른 방열 특성을 분석하 기 위해 배관 상부 및 하부의 콘크리트 두께를 100 $\mathrm{mm}$ 로 변화하여 3 개의 모델 조건에 대해 결과를 비 교하였다.

\section{2 시뮬레이션 조건 및 방법}

구체축열시스템과 인접해 있는 상 - 하부 공간의 실내온도는 $20^{\circ} \mathrm{C}$, 구조체 표면열전달율은 상 - 하부 각각 $9.26,6.13 \mathrm{~W} / \mathrm{m}^{2} \mathrm{~K}$ 로 설정하였고, 배관은 지름 $15 \mathrm{~mm}$, 두께 $1 \mathrm{~mm}$ 의 $\mathrm{PE}-\mathrm{X}$ 관을 사용하였으며, 각 재료별 물성치는 Table 2 와 같다. 전열해석은 1 분 간격으로, 24 시간에 걸쳐 진행하였고, 콘크리트 구 조체의 네 단면으로의 열손실은 없는 것으로 가정 하였다.

\section{3. 방열 특성 결과 분석}

공급 온수온도 및 유량에 따른 방열특성을 알아 보기 위해 평가모델 각각에 대해 상 - 하부 방열량, 공급온도 $\left(T_{s}\right)$, 환수온도 $\left(T_{r}\right)$, 방열면인 구조체 하부 표면의 18 개 지점에서의 표면온도 $\left(T_{s i}\right)$ 를 구하였다. 표면온도 분석 지점은 Fig. 1에 표시된 부분이다. 구체축열시스템은 매설배관 상하부 구조체의 열저 항 특성에 따라 상부방열량 및 하부방열량의 전달 비율이 달라질 수 있으므로, 단열재 및 마감재, 천 장재 등의 고려가 필요하다. 평가대상이 되는 구체 축열시스템은 배관매설층 상부에 단열재가 설치되 어 상부방열량이 하부방열량의 약 8 10\%로 나타 났으며, 본 연구에서는 하부방열량 및 단위면적(바 닥면적 $29.51 \mathrm{~m}^{2}$ )당 하부방열량을 방열량으로 평가 하였다. 방열량 특성 및 표면온도의 경우, 콘크리트 슬래브 하부 18 개 지점의 표면온도를 반영하여 평 균 표면온도 $\left(\overline{T_{s i}}\right)$ 를 산출하여 비교 분석하였다.

\section{1 공급 온수온도에 따른 방열특성}

공급유량 $3 \mathrm{LPM}$ 기준으로 공급온수온도를 $40^{\circ} \mathrm{C}$ 에서 $80^{\circ} \mathrm{C}$ 까지 $10^{\circ} \mathrm{C}$ 간격, 총 5 개의 평가모델(T1

Table 2 Thermal properties of materials

\begin{tabular}{c|c|c|c}
\hline Material & $\begin{array}{c}\text { Conductivity } \\
\left(\mathrm{W} / \mathrm{m}^{\circ} \mathrm{C}\right)\end{array}$ & $\begin{array}{c}\text { Density } \\
\left(\mathrm{kg} / \mathrm{m}^{3}\right)\end{array}$ & $\begin{array}{c}\text { Specific heat } \\
\left(\mathrm{J} / \mathrm{kg}^{\circ} \mathrm{C}\right)\end{array}$ \\
\hline Wood Flooring & 0.170 & 700 & 2070 \\
\hline Plain Concrete & 0.850 & 1600 & 930 \\
\hline Expended Polystyrene & 0.035 & 25 & 1470 \\
\hline Concrete Slab & 1.700 & 2300 & 930 \\
\hline PE-X Piping & 0.410 & 1200 & 1470 \\
\hline Water & - & 1000 & 4200 \\
\hline
\end{tabular}




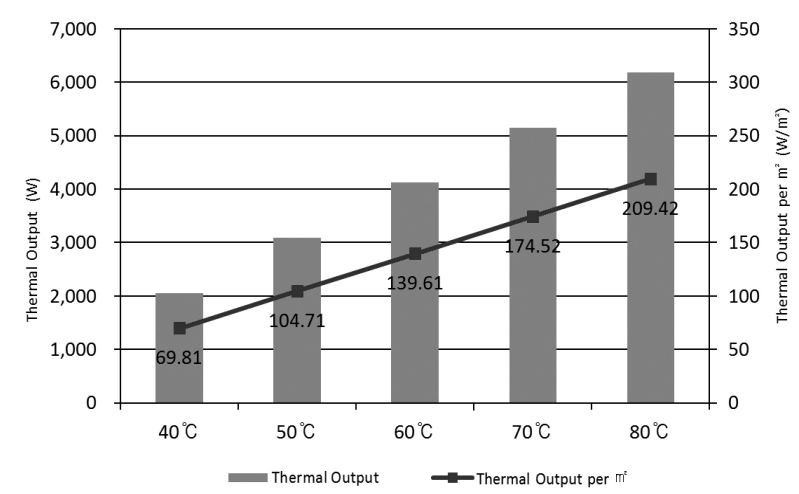

Fig. 3 Thermal output according to the supply water temperature variation(water flow rate $=3 \mathrm{LPM}$ ).

T5)에 대한 전열해석을 수행하였다. 공급 온수온도 에 따른 방열량 변화는 Fig. 3과 같이 공급 온수온도 가 상승함에 따라 선형으로 증가하였다. 공급온수온 도 $40^{\circ} \mathrm{C}, 60^{\circ} \mathrm{C}, 80^{\circ} \mathrm{C}$ 인 경우, 면적당 방열량은 각각 69.8, 139.6, $209.4 \mathrm{~W} / \mathrm{m}^{2}$ 로 나타났다. 환수온도강하는 공급온도 조건에서 각각 $12.0,18.0,24.0,30.0,36.0^{\circ} \mathrm{C}$ 로서, 거의 일정한 증가폭을 나타내며 증가하였다. 평균표면온도는 각각 $25.9,28.9,31.8,34.8,37.7^{\circ} \mathrm{C}$ 로 공급온도의 증가에 따라 일정하게 증가된 것을 확인 할 수 있었다(Table 3 참고), 공급온도에 따른 구조 체 하부 표면온도 분포특성은 공급온도 $80^{\circ} \mathrm{C}$ 인 경우 가 $40^{\circ} \mathrm{C}$ 인 경우에 비해 표면온도 분포의 표준편차가 약 $2.31^{\circ} \mathrm{C}$ 크며, 배관입구에서 배관출구까지의 표면 온도의 차이가 큰 것으로 나타났다(Table 3, Fig. 4의 (a), (b) 참고), 그러므로 실제 구체축열시스템 설계
에서는 실내 난방부하 및 구조체 하부 표면온도를 고려하여 최적화된 설계 공급 온수온도를 정할 필요 가 있는 것으로 판단된다. 공급 온수온도 $70,80^{\circ} \mathrm{C}$ 의 경우, 면적당 방열량이 매우 크지만, 평균 표면온도 가 매우 높아 거주자의 불쾌적에 대한 평가가 필요 한 것으로 판단된다.

\section{2 공급 유량에 따른 방열특성}

공급온도 $60^{\circ} \mathrm{C}$ 기준으로 공급 온수유량을 1 6 LPM 까지 총 6 개의 평가모델 $(\mathrm{F} 1 \sim \mathrm{F} 6)$ 에 대한 전열해석 을 수행하였다. 공급유량 1 6 LPM에 대해 면적당 방열량은 각각 68.1, 116.2, 143.5, 160.1, 171.3, 179.1 $\mathrm{W} / \mathrm{m}^{2}$ 으로 나타났으며, 그림 5 와 같이 공급 온수유량 이 상승함에 따라 방열량이 증가하였으나 증가폭은 점차 감소하였다. 환수온도 강하는 공급유량 $1 \sim 6$ $\mathrm{LPM}$ 에 대해 각각 $38.3,30.7,24.4,20.0,16.7,14.6^{\circ} \mathrm{C}$ 로, 공급유량이 증가할수록 환수온도강하는 감소하 였으며, 감소폭은 점차 줄어들었다. 향후 열원시스템 의 설계 및 운영조건을 고려하여 구체축열시스템의 공급유량 및 온도조건에 대한 평가가 필요할 것으로 판단된다. 공급유량이 증가할수록 평균 표면온도는 증가하였으며 유량증가에 따른 온도증가폭은 감소 하였다(Table 3 참고). 공급유량에 따른 구조체 하부 표면온도 분포특성은 공급유량이 $1 \mathrm{LPM}$ 인 경우, 배 관 인입부에서 배관 출구로 갈수록 온도분포가 뚜렷 이 나타나는 반면, $6 \mathrm{LPM}$ 인 경우는 전체 표면온도 가 고르게 나타나는 것을 확인할 수 있다(Table 3,

Table 3 Temperature differences between supply and return water, and average floor surface temperatures of test cases

\begin{tabular}{c|c|c|c|c}
\hline Test Case & $T_{r}\left({ }^{\circ} \mathrm{C}\right)$ & $T_{s}-T_{r}\left({ }^{\circ} \mathrm{C}\right)$ & $\left.T_{s i}{ }^{\circ} \mathrm{C}\right)$ & $\mathrm{SD}\left({ }^{\circ} \mathrm{C}\right)$ \\
\hline $\mathrm{T} 1$ & 28.0 & 12.0 & 25.9 & 1.2 \\
\hline $\mathrm{T} 2$ & 32.0 & 18.0 & 28.9 & 1.7 \\
\hline $\mathrm{T} 3$ & 36.0 & 24.0 & 31.8 & 2.3 \\
\hline $\mathrm{T} 4$ & 40.0 & 30.0 & 34.8 & 2.9 \\
\hline $\mathrm{T} 5$ & 44.0 & 36.0 & 37.7 & 3.5 \\
\hline $\mathrm{F} 1$ & 21.7 & 38.3 & 24.5 & 2.8 \\
\hline $\mathrm{F} 2$ & 29.2 & 30.7 & 28.8 & 2.7 \\
\hline $\mathrm{F} 3$ & 36.0 & 24.0 & 31.8 & 2.3 \\
\hline $\mathrm{F} 4$ & 40.0 & 20.0 & 32.7 & 1.8 \\
\hline $\mathrm{F} 5$ & 43.1 & 16.9 & 33.7 & 1.6 \\
\hline $\mathrm{F} 6$ & 45.4 & 14.6 & 34.4 & 2.3 \\
\hline $\mathrm{H} 1$ & 37.1 & 22.9 & 32.3 & 2.7 \\
\hline $\mathrm{H} 2$ & 36.5 & 23.5 & 35.0 & 2.4 \\
\hline $\mathrm{H} 3$ & 36.3 & 23.8 & 32.9 & \\
\hline
\end{tabular}




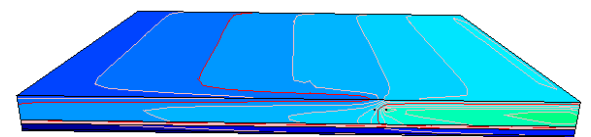

(a) $\mathrm{T} 1$

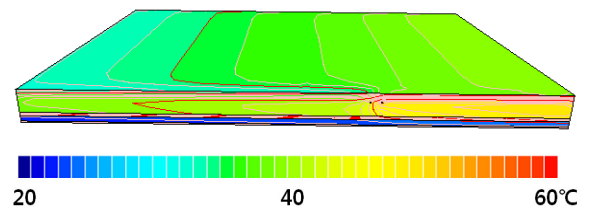

(b) $\mathrm{T} 5$

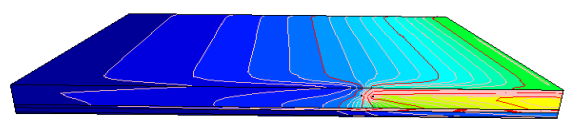

(c) F1

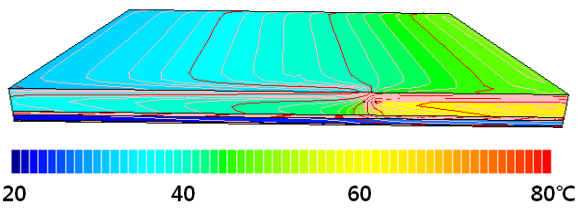

(d) F6

Fig. 4 Floor surface temperature distribution at the lower part of test case T1, T5, F1, F6.

Fig. 4의 (c), (d) 참고). 구체축열시스템의 설계 및 운 영에 있어서 고온수를 공급하여 저유량 범위에서 운 전하는 것보다는 저온수를 공급하고, 설계 유량을 크게 함으로써 바닥온도분포를 균일하게 유지할 수 있을 것으로 판단된다.

\section{3 콘크리트 축열량에 따른 방열특성}

콘크리트 축열량에 따른 방열특성을 알아보기 위해 배관층 상부 및 하부 콘크리트 구조체 두께 조건을 변화하여 Table 1과 같이 3개의 모델(H1 H3)에 대 해 시뮬레이션을 진행하였다. 총 4,320분(3일)에 걸친 시뮬레이션 결과, 기준 모델(H1)과 비교하여 상 하부의 슬래브 두께를 줄임으로써 축열량을 작게 한 경우(H3), Fig. 6과 같이 열적 반응시간이 다소 줄어드는 것을 알 수 있다. 배관 상부 슬래브 두께 만을 작게 한 경우 $(\mathrm{H} 2)$ 에는 축열량의 차이로 인해 기준 모델(H1)에 비해 반응시간이 다소 빨라짐을 알 수 있다. 즉, 하부방열량의 시간에 대한 특성은 콘크리트 구조체 두께가 얇아진 $\mathrm{H} 3$ 의 경우, 대략 2500 분 이후 일정하게 유지되었으며, $\mathrm{H} 2$ 의 하부방 열량은 기준 모델 $(\mathrm{H} 1)$ 에 비해 초기 반응속도는 다 소 빠르게 나타났으며, 시간이 경과함에 따라 기준 모델과 비슷한 온도 변화 패턴을 나타냄을 알 수 있었다. 구체축열시스템의 경우, 배관 상 - 하부 단 열 및 축열 조건에 따라서 상-하부 방열특성이 다 르게 나타나는데, 이처럼 배관 상-하부의 슬래브 두께를 변화시킴으로써 구조체의 열용량에 따른 반 응시간과 배관 상 - 하부의 열저항비에서 차이가 나 타나기 때문에 방열특성이 다르게 나타나는 것으로 판단된다. 구체축열시스템의 경우, HVAC 시스템 설계단계에서 공급 유량 및 온도 조건을 결정함에 있어서 구조체의 상 - 하부 단열 및 축열 특성을 반
영하여 시간 지연에 따른 운전 특성 및 피크부하 저감 효과에 대한 평가가 필요할 것으로 판단된다. 즉, 구체축열시스템의 경우, 신재생에너지나 미활용 에너지 등을 이용한 저온수 난방에서는 약 $30 \sim 60^{\circ} \mathrm{C}$ 의 온수가 공급될 수 있으며, 실내 부하 특성에 따 라 구조체의 시간지연에 따른 방열특성을 반영하여 운전계획을 수립하고 $\mathrm{HVAC}$ 시스템의 용량을 산정 하는 것이 필요하다.

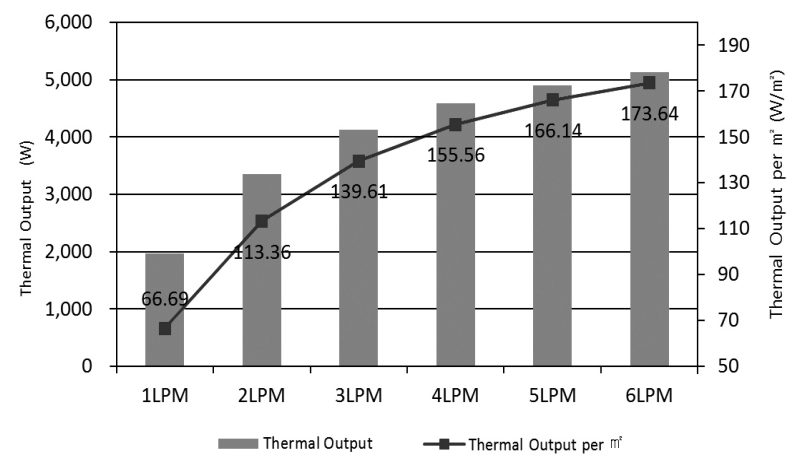

Fig. 5 Thermal output according to the supply water flow rate variation(supply water temperature $=60^{\circ} \mathrm{C}$ ).

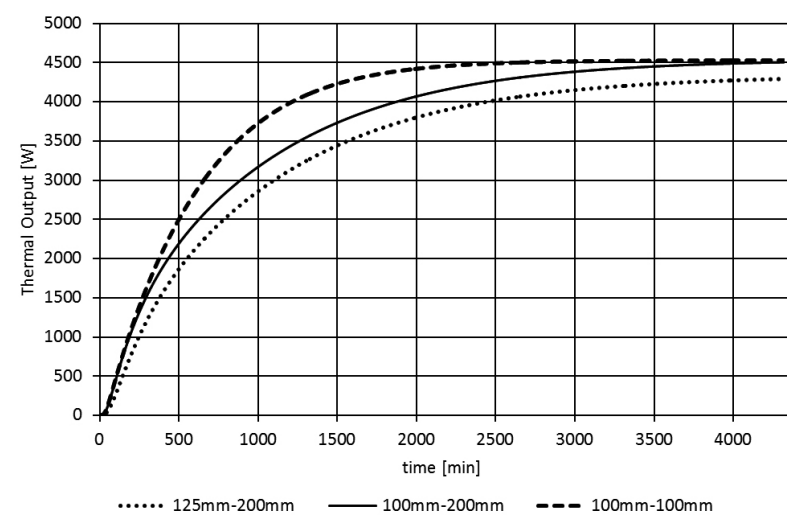

Fig. 6 Thermal output according to the concrete slab thickness variation. 


\section{4. 결 론}

오피스 건물에서 구체축열시스템을 적용하기 위 해서는 운전 조건에 따른 방열특성을 파악하는 것 이 필요하다. 구체축열시스템은 기존 대류 방식의 $\mathrm{HVAC}$ 시스템과 비교하여 구조체 축열로 인해 공 급되는 유량과 온도조건에 따라 동적으로 열적인 반응특성이 다르게 나타난다. 그러므로 본 연구에 서는 $\mathrm{FDM}$ 방법에 의한 전열해석 프로그램을 이용 하여 구체축열시스템의 공급온도 및 유량별 평가모 델에 대한 전열해석을 진행하여 방열특성을 살펴보 았다. 연구 결과를 요약하면 다음과 같다.

(1) 공급 온수온도 증가에 따라 방열량, 환수온도 강하, 평균 표면온도 모두 증가하였으며, 면적당 방 열량 및 평균 표면온도는 공급 온수온도 $40^{\circ} \mathrm{C}$ 일 때 89.6 W/ $\mathrm{m}^{2}, 27.2^{\circ} \mathrm{C}, 80^{\circ} \mathrm{C}$ 일 때 $268.7 \mathrm{~W} / \mathrm{m}^{2}, 41.5^{\circ} \mathrm{C}$ 로 나타났다.

(2) 공급 온수유량 증가에 따라 방열량, 평균 표 면온도가 증가하며 그 증가폭은 점차 감소하였고, 환수온도 강하폭은 점차 감소하였다. 면적당 방열 량 및 평균 표면온도는 공급 온수유량 $3 \mathrm{LPM}$ 일 때 $143.5 \mathrm{~W} / \mathrm{m}^{2}, 31.2^{\circ} \mathrm{C}, 6 \mathrm{LPM}$ 일 때 $179.1 \mathrm{~W} / \mathrm{m}^{2}, 34$. $4^{\circ} \mathrm{C}$ 로 나타났다.

(3) 콘크리트 슬래브 두께를 변화함으로써 구조 체의 열용량 및 배관 상 - 하부의 열저항비를 조절 하여 반응시간을 조절할 수 있었으며, 향후 HVAC 시스템 설계 단계에서 구조체 시간지연에 따른 방 열특성을 고려하여 설계 유량 및 공급온도 조건을 결정하고, 최적 운전계획을 수립하여 피크 부하 저 감 효과에 대한 평가가 필요할 것으로 판단된다.

또한 실제 건물에서 구체축열시스템의 설계/운전 시에는 실내 난방부하 및 열쾌적과 관련되어 공급 온수온도 및 유량을 결정해야 한다. 그러므로 추후 실제 $\mathrm{E}$ 건물에서 적용된 구체축열시스템을 대상으
로 냉난방기간 운전성능을 측정하여 최적화된 제어 및 운영방안을 도출하고자 한다.

\section{후기}

이 논문은 2011년도 정부(교육과학기술부)의 재 원으로 한국연구재단의 지원을 받아 수행된 기초연 구사업임(No. 2011-0014060).

\section{참고문헌}

1. Park, S. H., Kim, I. M., Koo, S. Y., Yeo, M. S., and, Kim, K. W., 2010, The effect on the heat output by combination of design factors of thermally activated building system (TABS), Journal of KIAEBS, Vol. 4 No. 3, pp. 180-186.

2. Park, S. H., Kim, I. M., Koo, S. Y., Yeo, M. S., and, Kim, K. W., 2009, An experimental evaluation on thermal performance of thermally activated building systems (TABS) for residential buildings, KIAEBS Fall Conference, pp. 171-174.

3. Markus Gwerder, Jüurg Tötli, Beat Lehmann, Franz Renggli, and Viktor Dorer., 2007, Control of thermally activated building systems, REHVA Wold Congress CLIMA 2007.

4. Beat Lehmann, Viktor Dorer, and Markus Koschenz., 2007, Application range of thermally activated building systems tabs, Energy and Buildings, Vol. 39, pp. 593-598.

5. Gwerder, M., Tödtli, J., Lehmann, B., Dorer, V., Güntensperger, W., and Renggli, F., 2006, Control of thermally activated building systems (TABS) in intermittent operation with pulse width $\mathrm{mo}^{-}$ dulation, Applied Energy, Vol. 86, pp. 1606-1616. 